\title{
Article/Artigo
}

\section{Carbohydrate-rich high-molecular-mass antigens are strongly recognized during experimental Histoplasma capsulatum infection}

\author{
Antígenos de alta massa molecular ricos em carboidratos são fortemente reconhecidos durante \\ infecção experimental por Histoplasma capsulatum
}

\author{
Fabrine Sales Massafera Tristão ${ }^{1}$, Paula César Leonello ${ }^{1}$, Luciene Airy Nagashima $^{1}$, Ayako Sano $^{2}$, Mário Augusto Ono ${ }^{1}$ \\ and Eiko Nakagawa Itano
}

\begin{abstract}
Introduction: During histoplasmosis, Histoplasma capsulatum soluble antigens (CFAg) can be naturally released by yeast cells. Because CFAg can be specifically targeted during infection, in the present study we investigated CFAg release in experimental murine histoplasmosis, and evaluated the host humoral immune response against high-molecular-mass antigens (hMMAg. $>150 \mathrm{kDa}$ ), the more immunogenic CFAg fraction. Methods: Mice were infected with $2.2 \times 10^{4}$ H. capsulatum IMT/HC128 yeast cells. The soluble CFAg, IgG anti-CFAg, IgG anti-hMMAg, and IgG-hMMAg circulating immune complexes (CIC) levels were determined by enzymelinked immunosorbent assay, at days $0,7,14$, and 28 post-infection. Results: We observed a progressive increase in circulating levels of CFAg, IgG anti-CFAg, IgG anti-hMMAg, and IgG-hMMAg CIC after H. capsulatum infection. The hMMAg showed a high percentage of carbohydrates and at least two main immunogenic components. Conclusions: We verified for the first time that hMMAg from $H$. capsulatum IMT/HC128 strain induce humoral immune response and lead to CIC formation during experimental histoplasmosis.
\end{abstract}

Keywords: Cell-free antigens. Histoplasmosis. Immune complexes.

\section{RESUMO}

Introdução: Durante a histoplasmose, os antígenos solúveis de Histoplasma capsulatum (CFAg) podem ser liberados naturalmente pelas células leveduriformes. Considerando que os CFAg constituem um alvo específico durante a infecção, no presente estudo nós investigamos a liberação de CFAg durante a histoplasmose murina experimental, e avaliamos a resposta imune humoral do hospedeiro contra antígenos de alta MM (hMMAg; $>150 \mathrm{kDa}$ ), altamente imunogênicos. Métodos: Camundongos foram infectados com $2.2 \times 10^{4}$ leveduras de $H$. capsulatum, cepa IMT/HC128. Os níveis de CFAg solúveis, IgG anti-CFAg, IgG anti-hMMAg, e também de imunocomplexos circulantes (CIC) IgG-hMMAgs foram determinados por ELISA nos dias 0, 7, 14 e 28 após a infecção. Resultados: Após a infecção por H. capsulatum, observamos um aumento progessivo de CFAg circulantes, IgG anti-CFAg, IgG anti-hMMAg, e também de CIC IgG-hMMAgs. Os hMMAg apresentaram alta porcentagem de carboidratos e, pelo menos, dois componentes imunogênicos. Conclusões: Mostramos pela primeira vez que os hMMAg de H. capsulatum cepa IMT/HC128 induzem resposta imune humoral e levam à formação de CIC durante a histoplasmose experimental.

Palavras-chaves: Antígenos solúveis. Histoplasmose. Imunocomplexos.

1. Departamento de Ciências Patológicas, Universidade Estadual de Londrina, Londrina, PR. 2. Medical Mycology Research Center, Chiba University, Chiba, Japan.

Address to: Dra. Eiko Nakagawa Itano. Dept ${ }^{\circ}$ de Ciências Patológicas/CCB/UEL. Campus Universitário, 86051-970 Londrina, PR, Brasil.

Phone: 5543 3371-4469; Fax: 5543 3371-4207

e-mail: itanoeiko@hotmail.com

Received in 13/04/2011

Accepted in 19/09/2011

\section{INTRODUCTION}

Histoplasmosis is a systemic fungal disease caused by the dimorphic fungus Histoplasma capsulatum var. capsulatum. The fungal cells grow in mycelial form at room temperature, with the conversion to yeast form occurring at $37^{\circ} \mathrm{C}$. Histoplasma capsulatum has a worldwide distribution throughout the subtropical and tropical zones ${ }^{1,2}$. When airborne mycelia (microconidia and mycelial fragments) are inhaled, they convert to yeast form in the host lungs ${ }^{3}$. Most cases are asymptomatically or self-limited to the lungs, due to an effective host defense linked to the cellular immune response. However, fungal replication can be reactivated from latent foci if the integrity of the host's immune system is impaired ${ }^{1,4-6}$.

Experimental histoplasmosis allows a better understanding of the disease in humans. Several features of the murine model are similar to those in humans, such as the pathology and the nature of the immune response to H. capsulatum antigens ${ }^{6}$.

During histoplasmosis, H. capsulatum cellfree antigens (CFAg) can be naturally released by the yeast cells. CFAg preparation has several positive characteristics, such as simple and quick preparation, and does not require sophisticated equipment. It is frequently used for diagnosis of paracoccidioidomycosis (PCM), a systemic mycosis caused by the fungus Paracoccidioides brasiliensis ${ }^{7}$. Moreover, CFAg can be used to evaluate cell immunity and to induce protection in a murine model of histoplasmosis 8 .

The presence of soluble antigens is frequently observed in human histoplasmosis, often in association with immunosuppression ${ }^{9-15}$. The study of these CFAg components is important if we consider that they are easily released components and therefore have the potential to interact with host components. 
A previous study by our group showed the in vitro hemagglutinin activity and syngeneic hemophagocytosis induction by H. capsulatum soluble antigens, and suggested that high-molecularmass components $(>150 \mathrm{kDa})$ could be responsible for the interaction with red blood cells ${ }^{16}$.

In the present study, we investigated the release of CFAg and highmolecular-mass antigens (hMMAg) during experimental infection with the H. capsulatum IMT/HC128 strain. Our results show for the first time evidence that H. capsulatum CFAg or hMMAg are released during experimental infection and induce humoral immune response and formation of circulating immune complexes (CIC). Moreover, our preliminary data of partial hMMAg characterization indicate that these antigens are carbohydrate-rich with at least two main immunogenic components.

\section{METHODS}

\section{Animals}

Male Swiss mice, 60 days old, obtained from the State University of Londrina Animal Facilities, were maintained under specific pathogenfree conditions in micro-isolator cages in the animal housing facility of the Center of Biological Sciences, State University of Londrina, Brazil. The animals were supplied with sterilized food and water ad libitum. Groups of 7-8 mice were used for each period of infection.

\section{Fungal strain and cell-free antigen preparation}

The $H$. capsulatum IMT/HC128 strain (kindly provided by Dr. V.R.B. Castillo, IMT/HC, Lima, Peru) was cultured at $35^{\circ} \mathrm{C}$ in Sabouraud agar (Micromed, Rio de Janeiro, Brazil) enriched with $5 \%$ goat serum and maintained by subculturing at 5-day intervals. CFAg was obtained as previously described by $P$. brasiliensis yeast cells $s^{7}$. Briefly, the fungal growth was collected by gently scraping the surface and was suspended in $1 \mathrm{ml}$ of phosphate buffered saline (PBS, pH 7.2), mixed for 30s on a Vortex-mixer and immediately centrifuged at $10.000 \mathrm{~g}$ for $60 \mathrm{~s}$. Next, the supernatant was mixed to phenylmethylsulfonyl fluoride (PMSF; Sigma, St. Louis, MO; 2.5mM) to reduce the activity of fungal natural proteases that may be liberated during antigen preparation. The supernatant was subsequently frozen and stored at $-80^{\circ} \mathrm{C}$. Protein concentration was determined using the Folin-phenol method ${ }^{17}$ with bovine serum albumin as a standard.

\section{Mice infection}

The H. capsulatum IMT/HC128 yeast cells were collected, washed in PBS, and counted in a hemocytometer. The concentration was adjusted to $2.2 \times 10^{5}$ cells $/ \mathrm{ml}$. The mice were intravenously infected (i.v.) with $100 \mu$ l of the fungal preparation described above, corresponding to $2.2 \times 10^{4}$ yeast cells. Control mice received sterile

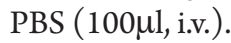

\section{Gel filtration chromatography and hMMAg fractions}

The CFAg chromatography was performed as previously described $^{16}$, with some modifications. Two milliliters of CFAg $(5.7 \mathrm{mg} / \mathrm{ml})$ were applied to a Sephadex G75-120 column (1.5 x $22 \mathrm{~cm}$, Sigma-Aldrich) buffered with PBS. Eluted samples $(1.5 \mathrm{ml}$ per tube) were collected in an automatic fraction collector and read into a spectrophotometer (UV/Visible, Ultrospec-2.000; Pharmacia Biotech, Auckland, Northland) at $280 \mathrm{~nm}$. For preliminary estimation of molecular mass, dextran blue [exclusion volume up to $150 \mathrm{kDa}$ ] was applied to the same column. The hMMAg fractions were identified according the absorbance profile, considering the samples that made up the first absorbance peak (fractions 7 to 10).

\section{IgG anti-CFAg and IgG anti-hMMAg preparation}

The IgG anti-CFAg was prepared both in New Zealand rabbits and Swiss mice (2-3 animals per group) by subcutaneous injection of CFAg $(250 \mu \mathrm{g}$ in rabbits and $75 \mu \mathrm{g}$ in mice $)$ emulsified in Freund's adjuvant $(\mathrm{v} / \mathrm{v})$. The first inoculation was performed with complete Freund's adjuvant and the two successive injections with incomplete Freund's adjuvant at intervals of two weeks. In addition, Swiss male mice were inoculated with $50 \mu \mathrm{g}$ hMMAg (pool of fractions 7 to $10, \mathrm{v} / \mathrm{v}$ ). After bleeding, the hyper immune serum was submitted through a Sepharose-protein G chromatography and the protein concentration was determined using the Folin-phenol method ${ }^{17}$ with bovine serum albumin as a standard.

\section{Determination of IgG anti-CFAg, IgG anti-hMMAg, and soluble antigens levels}

For determination of IgG anti-CFAg and anti-hMMAg levels, enzyme-linked immunosorbent assay (ELISA) immunoplates were coated (600ng, 100 $\mu \mathrm{l} /$ well) with IMT/HC128 CFAg or hMMAg (pool of fractions 7 to 10). After blocking with blocking solution [PBS-Tween $200.5 \%$ (PBS-T) plus 5\% (w/v) nonfat milk (Nestle)], plates were incubated with immune or non-immune mouse serum $\left(37^{\circ} \mathrm{C}, 1 \mathrm{~h}\right)$. After anti-mouse IgG peroxidase conjugate (Sigma A-8924; Sigma Chemical Co., St. Louis, MO) and substrate solution (5mg o-phenylenediamine - Sigma Chemical Co., St. Louis, MO, USA, $10 \mathrm{~mL}$ of $0.1 \mathrm{M}$ citrate buffer, $\mathrm{pH} 4.5$ and $10 \mu \mathrm{l} \mathrm{H}_{2} \mathrm{O}_{2}, 100 \mu \mathrm{l} /$ well) were added, the reaction was stopped with $50 \mu \mathrm{l}$ of $4 \mathrm{~N} \mathrm{H}_{2} \mathrm{SO}_{4} /$ well, and absorbance was read into a Titertek Multiscan EIA reader (Labsystems, Helsinki, Finland) at $492 \mathrm{~nm}$. For soluble antigens, immunoplates were coated with rabbit IgG anti-CFAg $(100 \mu \mathrm{l}, 100 \mathrm{ng}$ per well). After blocking with blocking buffer, plates were incubated with mouse serum (1:100 dilution, $\left.90 \mathrm{~min}, 37^{\circ} \mathrm{C}\right)$. Next, the mouse $\mathrm{IgG}$ anti-CFAg (600ng/well) was added, followed by anti-mouse IgG peroxidase conjugate, and processed as described above.

\section{Determination of immune complexes}

The IgG-hMMAg circulating immune complexes were detected in immune serum, as previously described ${ }^{18}$, with small modifications. Briefly, 70 $\mu$ l of serum were diluted in PBS (v/v) plus $140 \mu \mathrm{l}$ of polyethylene glycol 5\% (PEG 5\%) and incubated overnight at $4{ }^{\circ} \mathrm{C}$. After centrifugation $\left(3 \mathrm{~min}, 4^{\circ} \mathrm{C}, 300 \mathrm{~g}\right)$, the resulting precipitate was washed in $500 \mu \mathrm{l}$ of cold $2.5 \%$ PEG and centrifuged again. The precipitated immune complexes were dissolved in $100 \mu \mathrm{l}$ of blocking buffer containing $10 \mathrm{mM}$ EDTA and $0.02 \%$ sodium azide, and then incubated for $30 \mathrm{~min}$ at $37^{\circ} \mathrm{C}$. To increase the proportion of free antibodies, $40 \mu \mathrm{l}$ of $0.1 \mathrm{M} \mathrm{HCl}$-glycine buffer $(\mathrm{pH} 2.8)$ were added to each sample and neutralized with $70 \mu \mathrm{l}$ of $1 \mathrm{M}$ Tris ( $\mathrm{pH}$ 9.0). Then, $100 \mu \mathrm{l}$ of each sample were immediately dispensed in duplicate into immunoplates coated with CFAg (600ng, 100 $\mu \mathrm{l} /$ well). After blocking (blocking buffer), the technique was processed as described above for specific IgG detection.

\section{Western blotting assay}

The fractions 7, 8, 9, and 10, obtained after CFAg chromatography using a Sephadex G75-120 column, were individually mixed with reducing sample buffer $(6.5 \mathrm{mM}$ Tris- $\mathrm{HCl}, \mathrm{pH} 6.8 ; 2 \%$ sodium 
dodecyl sulfate (SDS), $10 \%$ glycerol, $10 \% \beta$-mercaptoethanol, and $0.05 \%$ bromphenol blue) and analyzed by SDS-polyacrylamide gel electrophoresis (SDS-PAGE) on a $7.5 \%$ to $20 \%$ gradient acrylamide gel using tris-glycine buffer, $\mathrm{pH}$ 8.2. Next, transference to a nitrocellulose membrane (NCM, GIBCO, Invitrogen Corporation, Long Island, New York, USA) was performed as previously described ${ }^{19}$. After blocking with blocking buffer, the NCM was incubated with rabbit $\operatorname{IgG}$ anti-CFAg $\left(1: 100,2 \mathrm{~h}, 37^{\circ} \mathrm{C}\right)$, followed by the addition of goat anti-rabbit IgG peroxidase (Sigma A-1949; Sigma Chemical Co., St. Louis, MO, 1:2.000, 90min, RT). The reaction was developed with a DAB solution (3,3-diaminobenzydine-4 $\mathrm{HCl}$; Sigma D-5637) according to the manufacturer's instructions and blocked with successive washes with distilled water. Protein standard (Invitrogen-Bench Mark prestained protein ladder; Invitrogen, Carlsbad, CA) was used according to the manufacturer's instructions.

\section{Carbohydrates analysis}

The carbohydrate analysis of the fractions eluted from Sephadex G75-120 column was performed using the Dubois method as previously described ${ }^{20}$. The results are expressed in optical density (O.D.) at $492 \mathrm{~nm}$.

\section{Statistical analysis}

Statistical analysis was performed using the parametric TukeyKramer test for two-group comparison (GraphPad software). Values of $\mathrm{p}<0.05$ were considered to indicate statistical significance. The results are expressed as the mean \pm SEM.

\section{Ethical considerations}

The Ethics Committee for Animal Experimentation of our university approved all experimental protocols described in the present study.

\section{RESULTS}

\section{IMT/HC128 CFAg are produced and recognized during experimental histoplasmosis}

To evaluate whether $H$. capsulatum IMT/HC128 cell-free antigens are produced after IMT/HC128 infection, we measured CFAg level in the serum from infected mice during experimental histoplasmosis. The antigenemy analysis showed the presence of CFAg in all evaluated time points (Figure 1). The amount of circulating soluble antigens increased during the line of infection $(0.100 \pm 0.06$ at 7 days, $0.13 \pm 0.03$ at 14 days, and $0.27 \pm 0.18$ at 28 days p.i.). No CFAg was detected in uninfected mice (Figure 1).

We next investigated the immune recognition of $H$. capsulatum IMT/HC128 cell-free antigens during experimental histoplasmosis. The specific IgG anti-CFAg was measured in the serum from IMT/ HC128 infected mice. As shown in Figure 2, all the IMT/HC128 infected mice produced IgG anti-CFAg. In addition, uninfected mice showed low IgG anti-CFAg synthesis $(0.079 \pm 0.01)$, which increased progressively according the course of infection $(0.093 \pm 0.025$ at 7 days, $0.11 \pm 0.04$ at 14 days, and $0.21 \pm 0.1$ at 28 days p.i.).

\section{The carbohydrate-rich hMMAg fractions have high antigenic potential}

To identify the antigenic fractions present in the CFAg preparation, the IMT/HC128 CFAg was first submitted to a Sephadex G75-120 column. Figure 3 shows the chromatography's

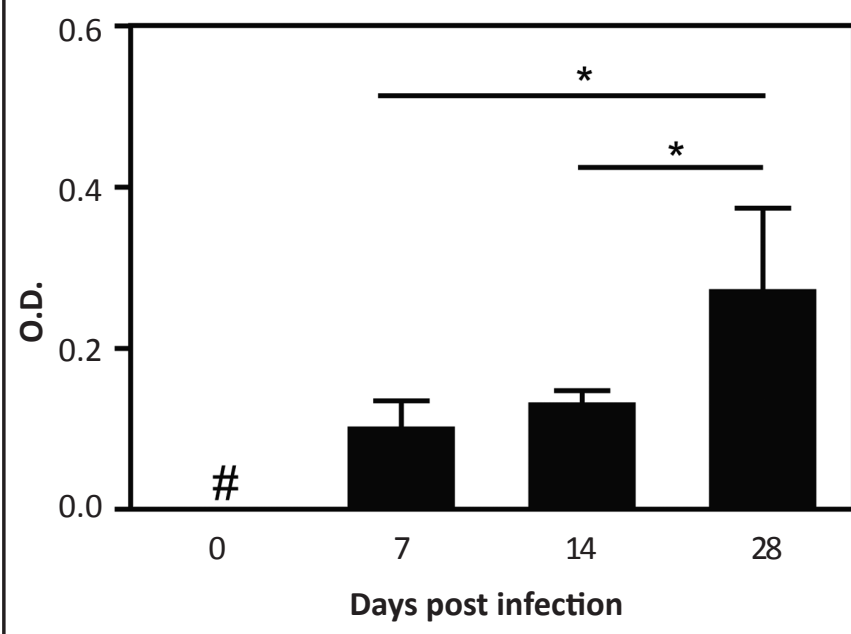

Swiss mice were challenged intravenously with $2.2 \times 10^{4}$ yeast forms of $\mathrm{H}$. capsulatum IMT/HC128 strain. The serum was collected at days $0,7,14$, and 28 p.i., and the CFAg level was evaluated as described in Methods. The results are expressed in optical density (O.D.) at $492 \mathrm{~nm}$, and the scale bars represent the mean \pm SEM. \#, not detected; ${ }^{*} p<0.05$.

FIGURE 1 - Cell-free antigens are detected in the serum during experimental histoplasmosis.

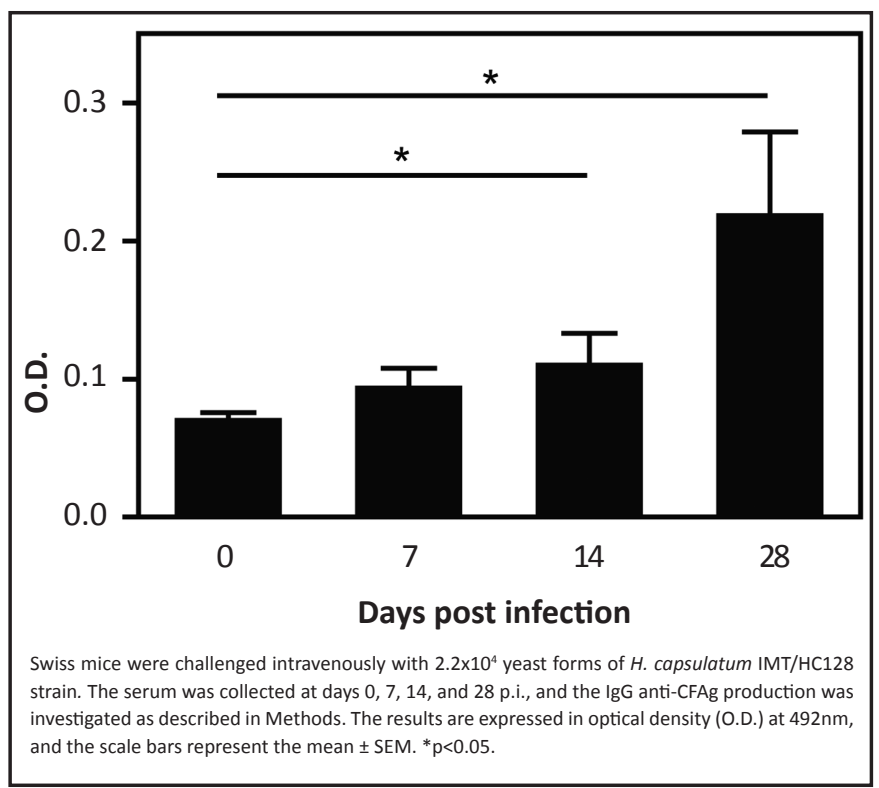

FIGURE 2 - Immunoglobulin G anti-cell free antigens are produced during experimental histoplasmosis.

elution profile $(280 \mathrm{~nm})$ of the 16 first collected samples. Our data clearly demonstrated a peak, which is shaped by fractions 7 to 13 , with highest value at point $8(0.19)$. The void volume marker, dextran blue, was eluted in fraction 8 (data not shown), indicating that samples collected in this tube have molecular mass corresponding to $>150 \mathrm{kDa}$. For this reason, the samples that draw the peak (fractions 7, 8, 9, and 10) were collectively named high-molecular-mass antigens (hMMAg).

The carbohydrate analysis of all collected samples showed a high amount of carbohydrate in most of hMMAg fractions (Figure 3). In detriment of fraction 7 , which has few carbohydrates $(0.18)$, fractions 8 (1.39), 9 (1.37), and 10 (0.58) are carbohydrate-rich samples, suggesting that hMMAg fractions have high antigenic potential during experimental IMT/HC128 infection.

In fact, when we performed a Dot-Plot assay using hMMAg samples, our results showed that hMMAg fractions are strongly 


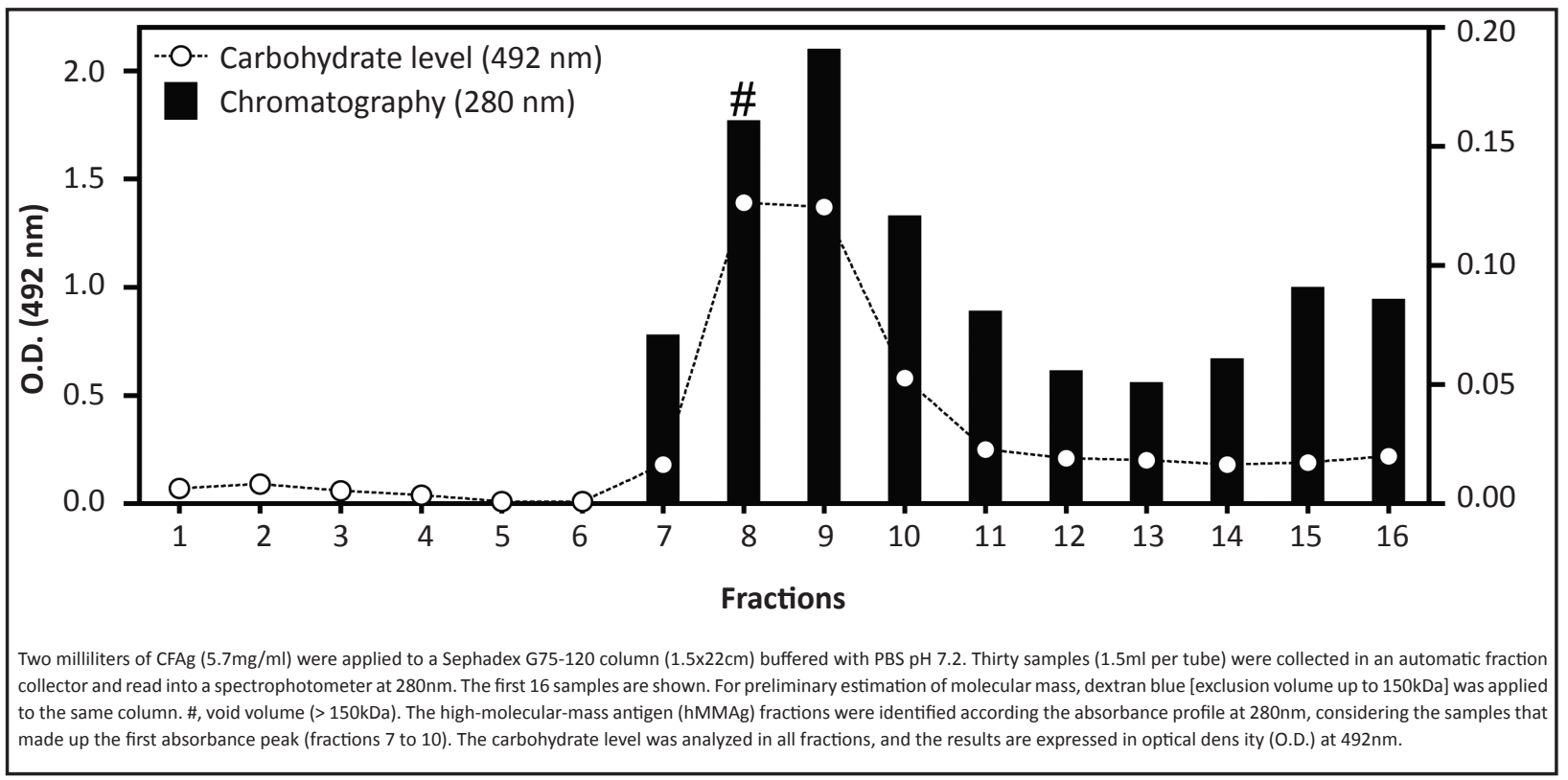

FIGURE 3 - H. capsulatum cell-free antigens chromatography profile and carbohydrates levels determination.

recognized by immune serum (data not shown). Moreover, our western blotting results indicate that all hMMAg fractions showed at least two main distinct bands when incubated with anti-CFAg serum (Figure 4). The first band has $\sim 113.7 \mathrm{kDa}$ and the second one, up to $150 \mathrm{kDa}(\sim 176 \mathrm{kDa})$.

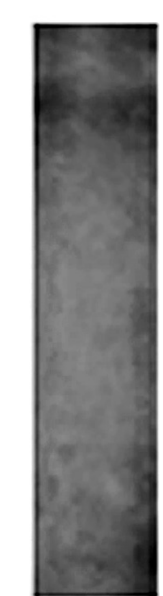

7

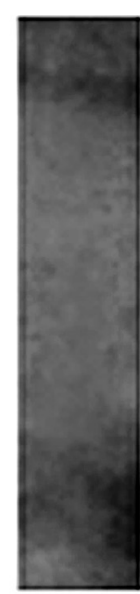

8

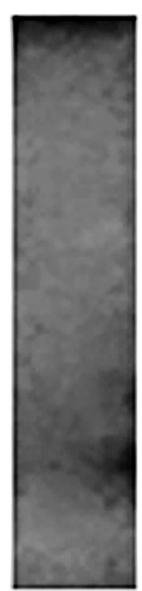

9

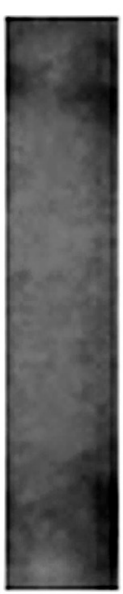

10
$-176.5$

$-113.7$

$-80.9$

Two milliliters of CFAg $(5.7 \mathrm{mg} / \mathrm{ml})$ were applied to a Sephadex G75-120 column $(1.5 \times 22 \mathrm{~cm})$ buffered with PBS pH 7.2. The fractions 7, 8, 9, and 10 were submitted to SDS-PAGE (polyacrilamide gel 7.5$20 \%$ ). After transference, the NCM was incubated with immune serum. The samples showed at least two components $(\sim 176 \mathrm{kDa}$ and $\sim 113 \mathrm{kDa})$ that are recognized during experimental histoplasmosis.

FIGURE 4 - Immunogenic components from hMMAg are recognized by antiCFAg serum.

\section{The specific IgG recognition of hMMAg leads to CIC formation}

Considering the presence of hMMAg in the serum from IMT/ HC128 infected mice, we next evaluated the host production of IgG anti-hMMAg. Our results showed higher levels of IgG anti-hMMAg in the immune serum, which increased progressively according the evolution of infection (Figure 5, left panel). At 14 (0.096 \pm 0.02) and 28 days p.i $(0.243 \pm 0.025)$, the amount of circulating IgG antihMMAg was significantly increased compared with uninfected serum $(0.043 \pm 0.015, \mathrm{p}<0.05)$.

To investigate whether binding of IgG anti-hMMAg and hMMAg leads to CIC, we evaluated the serum level of IgG-hMMAg CIC. As shown in Figure 5 (right panel), the CIC level was also elevated at $14(0.33 \pm 0.035)$ and 28 days p.i. $(0.26 \pm 0.02)$ in comparison with control not-infected serum $(0.036 \pm 0.025, \mathrm{p}<0.05)$.

Taken together, these results demonstrate that IMT/HC128 infection induces the production of IgG anti-hMMAg; this antibody can integrally bind to hMMAg, giving rise to CIC.

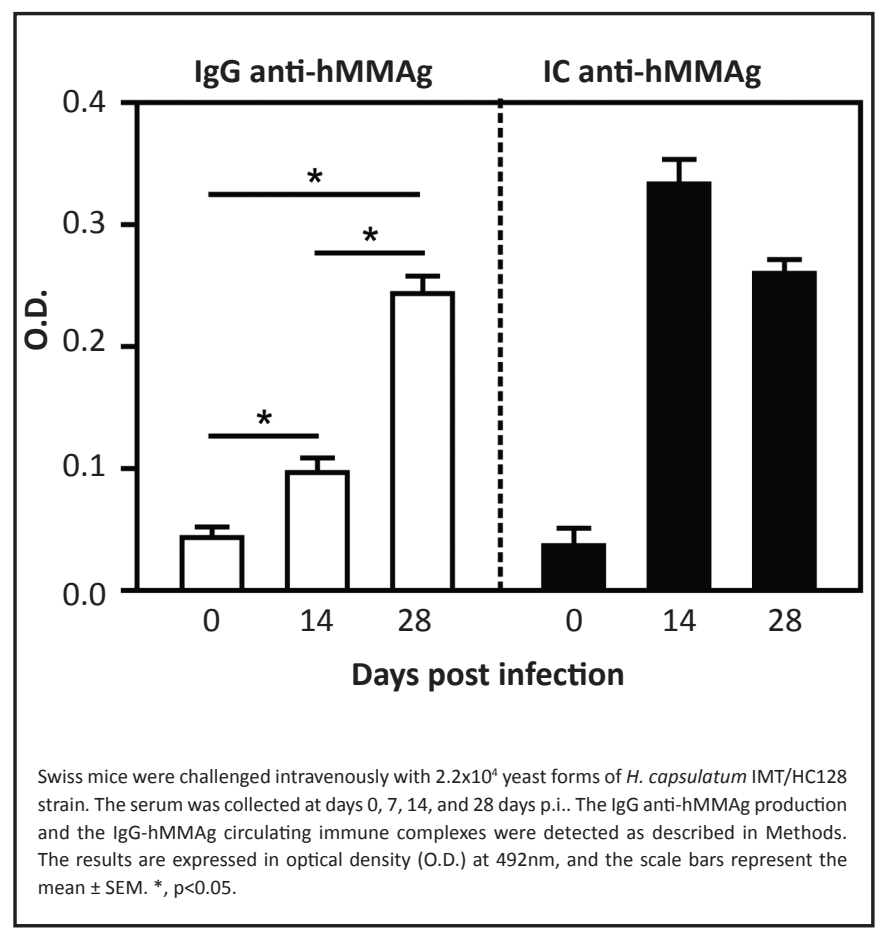

FIGURE 5 - Immunoglobulin G anti-high-molecular-mass-antigens are produced during experimental histoplasmosis and can give rise to Ig G-hMMAg immune complexes. 


\section{DISCUSSION}

During histoplasmosis, the $H$. capsulatum soluble antigens (CFAg) can be naturally released by the yeast cells, as observed in the CFAg preparation, or can result from fungal death by effective immune mechanisms. In this study, CFAg was detected in the serum during experimental histoplasmosis, mainly at day 28 p.i. These results could be due to natural antigen releasing, to fungal death by innate mechanism of defense in the early phase of infection and more effective action on fungal cells after adaptive immune response.

In agreement with our data, soluble antigens are frequently observed during human histoplasmosis ${ }^{9-15}$. These immunogenic components released by the yeast cells can constitute an escape mechanism from the host defense, since they can compete with the fungus surface antigens in the interaction with the antibodies produced by the host.

In addition, we observed progressively increased levels of circulating IgG anti-CFAg in the course of infection, suggesting the activation of humoral immune response against $H$. capsulatum soluble components. Although passive immunization on experimental histoplasmosis, using immune serum, does not lead to host protection or high titers of antibodies against $H$. capsulatum ${ }^{21}$, some studies have demonstrated the importance of some specific antibodies during fungal infections ${ }^{22}$.

During PCM, another systemic mycosis, previous results from our group showed higher levels of seric IgG anti-hMMAg in the serum from patients with the chronic form of PCM than in the serum from patients with the severe acute form ${ }^{23}$. In addition, our group showed the protective effect of previous immunization with hMMAg during experimental PCM in BALB/c mice ${ }^{24}$.

The $H$. capsulatum soluble antigens have hemagglutinin activity and syngeneic hemophagocytosis induction ${ }^{18}$. Considering the possible involvement of the high-molecular-mass components $(>150 \mathrm{kDa})$ in the interaction with the host red blood cells ${ }^{16}$, in this study we investigated the host humoral immune response against hMMAg during experimental murine histoplasmosis. Our results showed increased levels of IgG anti-hMMAg after infection, mainly at day 28 p.i. In addition, we observed high levels of IgG-hMMAg circulating immune complexes in the serum from infected mice, suggesting that CIC may be produced by increased levels of IgG anti-hMMAg and hMMAg in the serum from infected mice.

The detection of antibodies, soluble antigens, and CIC is important for diagnosis of histoplasmosis and follow-up therapy. Moreover, humoral response analysis allows a better understanding of the pathogenesis of the disease. Considering that CFAg, including hMMAg, are easily released components during the infection, future characterization of these soluble antigens could contribute to the comprehension of $H$. capsulatum pathogenicity.

The presence of soluble antigens or CIC in the plasma is associated with immunosuppression during $H$. capsulatum $m^{9-15,25,26}$ and P. brasiliensis infection ${ }^{27}$. In addition, the soluble antigens as CFAg or hMMAg can induce CIC formation, which could contribute to CIC diseases. In this context, the association of histoplasmosis and rheumatologic manifestations has been described ${ }^{28}$. Further studies are required to implicate whether the IgG-hMMAg CIC contribute to this manifestation.
The recognition of carbohydrates present or derived from fungal yeast allows the interaction with immune host cells allowing fungal recognition ${ }^{29}$. Previous work has established that the attachment and agglutination of $H$. capsulatum yeast cells to human erythrocytes is carbohydrate dependent ${ }^{29}$. Moreover, it was suggested that $H$. capsulatum soluble hMMAg can be involved in the interaction with red blood cells ${ }^{16}$.

When we partially characterized the hMMAg fraction, the carbohydrate analysis showed high amounts of carbohydrate in the hMMAg chromatography's fractions. These samples were strongly recognized by immune serum (data not shown) and consisted of at least two main immunogenic components. One component with $\sim 176 \mathrm{kDa}$ is compatible with sephadex results. On the other hand, the $\sim 113 \mathrm{kDa}$ component does not show compatibility with gel filtration results. Probably the reduction conditions used in SDS-PAGE generated subcomponents from hMMAg, which were detected by western blotting data.

In conclusion, we verified for the first time that CFAg and hMMAg from $H$. capsulatum IMT/HC128 strain induce humoral immune response and lead to high-molecular-mass CIC formation during experimental murine histoplasmosis.

\section{ACKNOWLEDGMENTS}

The authors thank Nilson de Jesus Carlos and Mari Sumigawa Kaminami for their technical assistance.

\section{CONFLICT OF INTEREST}

The authors declare that there is no conflict of interest.

\section{FINANCIAL SUPPORT}

This work was supported by grants from Fundação Araucária/ PR, CNPq and PROPPG/UEL.

\section{REFERENCES}

1. Schwarz J. The organism Histoplasma capsulatum. Histoplasmosis. New York: Praeger Publishers; 1981. p. 12-51.

2. Maresca B, Kobayashi GS. Dimorphism in Histoplasma capsulatum: a model for the study of cell differentiation in pathogenic fungi. Microbiol Rev 1989; 53:186-209.

3. Eissenberg LG, Goldman WE. Histoplasma variation and adaptive strategies for parasitism: new perspectives on histoplasmosis. Clin Microbiology Rev $1991 ; 4: 411-421$

4. Ramdial PK, Mosam A, Dlova NC, Satar NB, Aboobaker J, Singh SM. Disseminated cutaneous histoplasmosis in patients infected with human immunodeficiency virus. J Cutan Pathol 2002; 29:215-225.

5. Salzman SH, Smith RL, Aranda CP. Histoplasmosis in patients at risk for the acquired immunodeficiency syndrome in a nonendemic setting. Chest 1988; 93:916-921.

6. Deepe GS. Immune response to early and late Histoplasma capsulatum infections. Curr Opin Microbiol 2000; 3:359-362.

7. Camargo ZP, Taborda CP, Rodrigues EG, Travassos LR. The use of cell-free antigens of Paracoccidioides brasiliensis in serological tests. J Med Vet Mycol 1991; 29:31-38.

8. Sa-Nunes A, Medeiros AI, Nicolete R, Frantz FG, Panunto-Castelo A, Silva CL, et al. Efficacy of cell-free antigens in evaluating cell immunity and inducing protection in a murine model of histoplasmosis. Microbes and infection/Institut Pasteur $2005 ; 7: 584-592$ 
9. Torres M, Diaz H, Herrera T, Sada E. Evaluation of enzyme linked immunosorbent-assay and western blot for diagnosis of histoplasmosis. Rev Invest Clin 1993; 45:155-160.

10. Hamilton AJ. Serodiagnosis of histoplasmosis, paracoccidioidomycosis and penicilliosis marneffei; current status and future trends. Med Mycol 1998; 36:351-364.

11. Durkin MM, Connolly PA, Wheat LJ. Comparison of radioimmunoassay and enzyme-linked immunoassay methods for detection of Histoplasma capsulatum var. capsulatum antigen. J Clin Microbiol 1997; 35:2252-2255.

12. Guimarães AJ, Pizzini CV, De Matos Guedes HL, Albuquerque PC, Peralta JM, Hamilton AJ, et al. ELISA for early diagnosis of histoplasmosis. J Med Microbio 2004; 53:509-514.

13. Garringer TO, Wheat LJ, Brizendine EJ. Comparison of an established antibody sandwich method with an inhibition method of Histoplasma capsulatum antigen detection. J Clinical Microbiol 2000; 38:2909-2913.

14. Wheat LJ, Cloud G, Johnson PC, Connolly P, Goldman M, Le Monte A, et al. Clearance of fungal burden during treatment of disseminated histoplasmosis with liposomal amphotericin B versus itraconazole. Antimicrob Agents Chemother 2001; 45:2354-2357.

15. Wheat LJ, Garringer T, Brizendine E, Connolly P. Diagnosis of histoplasmosis by antigen detection based upon experience at the histoplasmosis reference laboratory. Diagn Microbiol Infect Dis 2002; 43:29-37.

16. Vivan RH, Leonello PC, Nagashima LA, Kaminami MS, Tristão FSM, Sano A, et al. Soluble components of Histoplasma capsulatum var. capsulatum have hemagglutinin activity and induce syngeneic hemophagocytosis in vitro. Mycopathol 2010; 169:151-157.

17. Lowry OH, Rosebrough NJ, Farr AL, Randall RJ. Protein measurement with the Folin phenol reagent. J Biol Chem 1951; 193:265-275.

18. Unterkircher CS, Yazaki SC, Shimizu MT, Jorge AO, Camargo ZP Specific components found in circulating immune complexes (CIC) in paracoccidioidomycosis. J Med Vet Mycol 1996; 34:273-277.

19. Towbin H, Staehelin T, Gordon J. Electrophoretic transfer of proteins from polyacrylamide gels to nitrocellulose sheets: procedure and some applications. Proc Natl Acad Sci USA 1979; 76:4350-4354.

20. Dubois M, Gilles K, Hamilton JK, Rebers PA, Smith F. A colorimetric method for the determination of sugars. Nature 1951; 168:167.

21. Allendoerfer R, Magee DM, Deepe Jr GS, Graybill JR. Transfer of protective immunity in murine histoplasmosis by a CD4+ T-cell clone. Infection and Immunity 1993; 61:714-718.

22. Kamel SM, Wheat LJ, Garten ML, Bartlett MS, Tansey MR, Tewari RP. Production and characterization of murine monoclonal antibodies to Histoplasma capsulatum yeast cell antigens. Infection Immunity 1989; 57:896-901.

23. Marquez AS, Vicentini AP, Ono MA, Watanabe MA, de Camargo ZP, Itano EN. Reactivity of antibodies from patients with acute and chronic paracoccidioidomycosis to a high molecular mass antigen from Paracoccidioides brasiliensis. J Clin Lab Anal 2005; 19:199-204.

24. Pavanelli WR, Kaminami MS, Geres JR, Sano A, Ono MA, Camargo IC, et al. Protection induced in BALB/c mice by the high-molecular-mass ( $\mathrm{hMM}$ ) fraction of Paracoccidioides brasiliensis. Mycopathol 2007; 163:117-128.

25. Bullock W, Artz R, Bhathena D, Tung K. Histoplasmosis. Arch Intern Med 1979; 139:700-702.

26. Kauffman CA. Histoplasmosis: a clinical and laboratory update. Clin Microbiol Rev 2007; 20:115-132.

27. Brummer E, Castaneda E, Restrepo A. Paracoccidioidomycosis: an update. Clin Microbiol Rev 1993; 6:89-117.

28. Rosenthal J, Brandt KD, Wheat LJ, Slama TG. Rheumatologic manifestations of histoplasmosis in the recent Indianapolis epidemic. Arthritis Rheum $1983 ; 26: 1065-1070$

29. Taylor ML, Duarte-Escalante E, Perez A, Zenteno E, Toriello C. Histoplasma capsulatum yeast cells attach and agglutinate human erythrocytes. Med Mycol 2004; 42:287-292. 